\title{
CORRIGENDUM
}

\section{Inhibition of NF- $\kappa$ B sensitizes human pancreatic carcinoma cells to apoptosis induced by etoposide (VP16) or doxorubicin}

\author{
Alexander Arlt, Jens Vorndamm, Maike Breitenbroich, Ulrich R Fölsch, Holger Kalthoff, \\ Wolfgang E Schmidt and Heiner Schäfer
}

DOI: $10.1038 / \mathrm{sj} /$ onc/1205379

Correction to: Oncogene (2001) 20, 859-868

Since the publication of the above paper, the authors have identified an error in the text. The authors wish to apologise for this error and have issued the following statement:

In the manuscript entitled 'Inhibition of NF- $\kappa \mathrm{B}$ sensitizes human pancreatic carcinoma cells to apoptosis induced by etoposide (VP16) or Doxorubicin' published in Oncogene (2001) 20, 859-868, we described two cell lines as being highly resistant to VP16 and doxorubicin treatment and exhibiting very low constitutive NFkappaB activity. In error, one of these two cell lines was misnamed BxPc-3 throughout the entire manuscript instead of T3M4. Therefore, all data shown in the manuscript as well as the conclusions referring to BxPc-3 cells should be assigned to T3M4 cells. Accordingly, our study compared two chemoresistant cell lines - 'Capan-1' and 'A818-4' exhibiting high basal NFkappaB activity with two sensitive cell lines - 'PT45-P1' and 'T3M4' (not BxPc3) exhibiting low NFkappaB activity. 